\title{
Effects of Treadmill Training in chronic hemiparetic: a randomized, double-blind clinical trial
}

\author{
Wildja de Lima Gomes', Luciara Irene de Nadai Dias², Rachel Paes Guimarães², Cínthia Mara Stivali², \\ Gisele da Rosa Faria² Ana Carolina Nunes Bovi³, Ênio Walker de Azevedo Cacho', Roberta de Oliveira Cacho', \\ Núbia Maria Freire Vieira Lima'
}

\begin{abstract}
Background: It is estimated that the prevalence of cerebrovascular accident (CVA) increases significantly as a result of the increase in the elderly population, leading to dependence and care. Interventions with physical exercises are essential for patients with chronic CVA and hemiparesis to contribute to functional motor recovery. The gait of the hemiparetic patients is very impaired, including decreased speed, unipodal support in the abbreviated paretic limb, increased step length, decreased hip flexion, increased knee flexion and plantar flexion and involves compensatory strategies to deal with deficits of the affected limb. Rehabilitation programs of patients with CVA should focus on the restoration of the individual's independence and ability to move. Objective: To analyze the effects of the addition of a load on a lower limb not affected in the discharge of weight and motor function of paretic lower limb. Method: Experimental, randomized, double-blind study conducted at the Physiotherapy and Occupational Therapy Outpatient Clinic of the Hospital das Clínicas (HC) - UNICAMP. Participants were assessed by the Confidence and Balance Scale, Fugl-Meyer Assessment of Physical Performance (FMA), Modified Ashworth Scale (MAS), Postural Stroke Scale for post-stroke patients (PSS), Time up and go test (TUG), 10-Meter gait test, Stroke Scale Barthel and weight transfer in the affected lower limb. Participants were treated in 12 walking training sessions on the treadmill with $1 \mathrm{~kg}$ added to the ankle of the lower limb. Results: There were variations between the 3 times for gait time $(p=0.005)$, FMA ( $p=0.002)$, Activities-specific Balance Confidence Scale (ABC scale) $(p=0.007)$ and EAPA ( $p=0.042)$. Conclusion: Treadmill therapy and weight addition in the healthy limb revealed improvement in motor function, balance in orthostatism and walking speed.
\end{abstract}

Keywords: Paresis; Stroke; Gait; Lower Extremity.

\section{INTRODUCTION}

It is estimated that the prevalence of cerebrovascular accident (CVA) increases significantly as a result of the increase in the elderly population, leading to dependence and care. Of the subjects with CVA, only $12 \%$ are independent to perform the daily activities in the acute phase of the disease, and in the chronic phase from 25 to $74 \%$ require assistance for activities such as food, self-care and mobility ${ }^{(1,2)}$. Peoples with CVA have decreased physical fitness and worse cardiovascular health due to the decrease in their activities ${ }^{(3)}$. Interventions with physical exercises are essential for patients with chronic CVA and hemiparesis to contribute to functional motor recovery ${ }^{(4)}$. The gait of the hemiparetic patients is very impaired, including decreased speed, unipodal support in the abbreviated paretic limb, increased step length, decreased hip flexion, increased knee flexion and plantar flexion and involves compensatory strategies to deal with deficits of the affected limb $b^{(5)}$. Rehabilitation programs of patients with CVA should focus on the restoration of the individual's independence and ability to move ${ }^{(6)}$. The gait training is an effective strategy to improve the gait pattern of these patients, with treadmill training being considered therapy that optimizes the interpretation of the normal sensory input of gait ${ }^{(7,8)}$. Rehabilitation techniques based on the principle of repetitive exercises and oriented tasks can significantly improve lower limb motor and functional skills in hemiparetic ${ }^{(9)}$. Gjellesvik et al. in their study, used exercise on the treadmill and demonstrated improvement of the cardiovascular conditioning and functional gait improvements, evaluated through the 6-minute walk test (6MWT), 10m test and Time Up and Go test (TUG) ${ }^{10}$. Lam at al., also used the $6 \mathrm{MWT}$ and $10 \mathrm{~m}$ test, in 52 participants who performed aerobic exercises on a treadmill, demonstrating that there was an improvement in walking speed ${ }^{(11)}$. Tyrell et al., in their randomized clinical trial, with 20 patients with CVA who underwent treadmill training at three times: their walking speed, faster speed and intermediate speed, showed significant improvements in the length of the step of

Corresponding author: Wildja de Lima Gomes. Address: Rua Vila Trairi, s/n, Bloco 2, Gabinete 2 - Centro. Faculdade de Ciências da Saúde do Trairi da Universidade Federal do Rio Grande do Norte (UFRN). CEP: 59200-000 - Santa Cruz - RN, Brazil. Phone: +55 84 98821-4705. E-mail: wildjalima@hotmail.com

1. Faculdade de Ciências da Saúde do Trairí (FACISA), Universidade Federal do Rio Grande do Norte - UFRN - Santa Cruz (RN), Brazil.

Full list of author information is available at the end of the article.

Financial support: The authors declare that there was no financial support.

Submission Date: 12 October 2017; Acceptance Date: 08 December 2017; Publication Date: 28 December 2017 
both lower limbs, in the extension of the paretic hip, better positioning in the paretic limb and more knee flexion in the balance phase ${ }^{(12)}$. In the scientific literature there are still questions about treadmill training in hemiparetic patients due to CVA, which need to be listed and discussed. So the purpose of this study is to investigate the effects on motor function of the paretic lower limb with load placement in the not affected lower limb.

\section{METHODS}

It's an experimental, randomized, double-blind study conducted at the Physiotherapy and Occupational Therapy Outpatient Clinic of the Hospital das Clínicas (HC) - UNICAMP. Volunteers, aged between 20 and 70 years, victims of single event of chronic CVA (more than six months post-CVA), ischemic or hemorrhagic, capable of independently walking for 10 meters without any type of assistance were included in this study. Those who presented comprehension disorders or orthopedic and / or neurological comorbidities were excluded. All participants signed a Free and Informed Consent Term previously approved by the Research Ethics Committee of the UNICAMP. (CAAE 0872.0.146.000-08, protocol 1103/08)

\section{Measuring Instruments}

Participants were assessed by the following instruments. The Modified Ashworth Scale (MAS) was used to evaluate the degree of muscular resistance to passive movement, being used only the lower section member. The score of each item ranges from 0-4, with 0 representing normal tone and 4 rigidity due to hypertonia ${ }^{(13)}$.

Fugl-Meyer Assessment of Physical Performance (FMA) is a scale designed to evaluate hemiplegic patients after CVA and measures the motor function of upper and lower passive mobility, pain, sensitivity and balance. Each item is scored from 0 to 2, and the lower the score the worse the patient's functional capacity. Only the parts related to the lower limbs were used in this study ${ }^{(14)}$. In the TUG test, the subjects are instructed to get up from a chair, walk for 3 meters, turn around, return to the chair and sit back on it. The time required to perform this task was measured with a stopwatch ${ }^{(15)}$. Postural Stroke Scale for post-stroke patients (PSS) - is composed of 12 items divided into two subscales, with five items evaluating the maintenance of the posture (MAP) and the remaining seven items evaluating the posture change (MUP) (in sitting, lying and standing postures). Each item can be scored from 0 to 3 , being 3 when the task is performed independently and declining the score as the patient would need more help from the therapist. The maximum scores of the MAP and MUP subscales are 15 and 21 respectively. The PSS minimum total score is 0 (worst) and the maximum is 36 (best function) ${ }^{(16)}$. In the 10-meter gait test, the participant is asked to walk for 10 meters and the therapist evaluates the cadence, step length and gait speed using a stopwatch. The test is performed 3 times considering the mean values ${ }^{(17)}$. The Barthel Scale measures the degree of care required in 10 activities, i.e. the level of independence in self-care activities such as food, personal hygiene, dressing, bladder, bowel control, walking, climbing stairs and chair transfer to bed. The score is $0,5,10$ and 15. The note is proportional to the independence, so the higher the score the more independent the patient. The maximum score is 100, and below 50 means dependency ${ }^{(18)}$. Confidence and Balance Scale - Consists of a 16-item questionnaire that can be completed by the patient or administered by the therapist. Patient confidence in performing 16 activities in the home is scored from 0 (no trust) to 100 (total trust). Points closer to 100 are the best on this scale ${ }^{(19)}$. Body Mass Measurement was measured using a digital scale during the initial and final evaluation, in order to verify if there was a change in body mass. Weight Discharge Measure was measured through two conventional digital scales. The participant was asked to step up with one foot on each scale and the therapist observed the weight discharge in each limb. Two simple digital scales (brand Britânia ${ }^{\circledR}$, electronic model BE3 and capacity for $150 \mathrm{~kg}$ or 330 pounds each scale) were used, which were calibrated for use.

\section{Procedures}

The simple randomization was performed according to the participants' entry in the research and the subjects were randomly allocated in the experimental group and in the control group, respectively. They were evaluated by all the above instruments and the evaluator did not participate in the treatment (blind). The volunteers underwent a total of 12 sessions performed 2 times a week for 6 weeks. The experimental group performed gait training on the treadmill for 20 meters with the addition of a shinguard to its unaffected lower limb (ankle - shin region), with a load of $1 \mathrm{~kg}$ for women and $3 \mathrm{~kg}$ for men. The control group performed conventional treatment twice a week for 6 weeks. When patients were unable to support both hands on the treadmill as a result of the deficits, a sling on the upper limb was used in order to avoid compensatory movements. If necessary, participants were allowed to rest for $1 \mathrm{~min}$, not altering the total time of the 20-minute walking training. The same evaluator performed the final evaluation, post-treatment, at the end of the proposed sessions and the follow-up after 45 days of the end of the sessions using the same instruments previously mentioned.

\section{STATISTICAL ANALYSIS}

A descriptive analysis of the demographic data and initial variables was performed. There was no normal distribution of variables (Shapiro-Wilks test). To compare the results of the evaluations (pre-treatment, post-treatment and followup) the Wilcoxon test was used for related samples. Values of $p<0.05$ were used as statistically significant. It was used the 
statistical software SPSS 17.0, Windows version (SPSS Inc., Chicago, IL, USA).

\section{RESULTS}

In this study, 13 patients with CVA diagnosis were randomly assigned to treatment group $(T G, n=7)$ and control group (CG, $n=6$ ). Demographic data are shown in table 1 . Tables 2 and 3 show the scores of the measuring instruments in the pre-treatment, post-treatment and follow-up periods. Figure 1 shows the PSS scores in the different periods.

\section{DISCUSSION}

Chronic hemiparesis has a negative impact on mobility and many factors contribute to post-CVA functional disability, such as reduction of cardiovascular fitness, increased energy spent during locomotion, poor motor control, deficiency in lower limb stretching, disuse atrophy, and abnormal biomechanics of gait. The gait variations caused by hemiparesis commonly imply activity intolerance, promoting sedentary habits and physical deconditioning ${ }^{(9)}$. In the randomized clinical trial of Yen et al. ${ }^{(20)}$ with 14 subjects, experimental group $(n=7)$ and control group $(n=7)$, used a protocol that included stretching strengthening, balance training, ground walking training for both groups and for the experimental group was added gait training on treadmill with partial weight support for 30min, 3 times a week for 4 weeks, being observed that the experimental group presented better motor performance, with the increase of the speed, step length of both limbs and induction of greater corticomotor excitability. They further recommended the use of
Table 1- Demographic data

\begin{tabular}{|c|c|c|c|c|c|c|}
\hline \multirow{2}{*}{ Variables } & \multicolumn{3}{|c|}{ Treatment group $(n=7)$} & \multicolumn{3}{|c|}{ Control group $(n=6)$} \\
\hline & Median & $\begin{array}{c}10 \\
\text { quartile }\end{array}$ & $\begin{array}{c}30 \\
\text { quartile }\end{array}$ & Median & $\begin{array}{c}10 \\
\text { quartile }\end{array}$ & $\begin{array}{c}30 \\
\text { quartile }\end{array}$ \\
\hline $\begin{array}{l}\text { Gender } \\
\text { (F/M) }\end{array}$ & $3 / 4$ & & & $2 / 4$ & & \\
\hline Age (years) & 47 & 23 & 51 & 45 & 25.5 & 54.25 \\
\hline $\begin{array}{l}\text { Injury time } \\
\text { (years) }\end{array}$ & 7 & 2 & 8 & 3.5 & 2.5 & 6.75 \\
\hline Height & 1.7 & 1.48 & 1.73 & 1.69 & 1.61 & 1.72 \\
\hline Weight (kg) & 80.9 & 71.6 & 94.9 & 73.9 & 57.35 & 88.3 \\
\hline $\begin{array}{l}\text { NA Weight } \\
(\mathrm{kg})\end{array}$ & 48.4 & 34.6 & 55.7 & 35.3 & 27.93 & 42.3 \\
\hline $\begin{array}{l}\text { AF Weight } \\
\text { (kg) }\end{array}$ & 39.5 & 21.5 & 46.5 & 40.1 & 24.85 & 44.33 \\
\hline
\end{tabular}

Note: $F=$ female; $M=$ male; $N A=$ Non-affected; $A F=$ affected.

Table 2 - Variation of weight discharge values of the lower limb per group.

\begin{tabular}{|c|c|c|c|c|c|c|}
\hline \multirow[b]{2}{*}{ Variables } & \multicolumn{3}{|c|}{ Treatment group $(n=7)$} & \multicolumn{3}{|c|}{ Control group $(n=6)$} \\
\hline & Median & $\begin{array}{c}10 \\
\text { quartile }\end{array}$ & $\begin{array}{c}3 \circ \\
\text { quartile }\end{array}$ & Median & $\begin{array}{c}10 \\
\text { quartile }\end{array}$ & $\begin{array}{c}\text { 3을 } \\
\text { quartile }\end{array}$ \\
\hline $\begin{array}{l}\text { Pre AF } \\
\text { weight }\end{array}$ & 39.5 & 21.5 & 46.5 & 40.1 & 24.85 & 44.33 \\
\hline $\begin{array}{l}\text { Post AF } \\
\text { weight }\end{array}$ & 39.2 & 24.2 & 48.1 & 36.65 & 28.68 & 44.15 \\
\hline $\begin{array}{l}\text { Follow-up } \\
\text { AF weight }\end{array}$ & 42.6 & 26.7 & 45.8 & --- & --- & --- \\
\hline
\end{tabular}

Note: $A F=$ affected

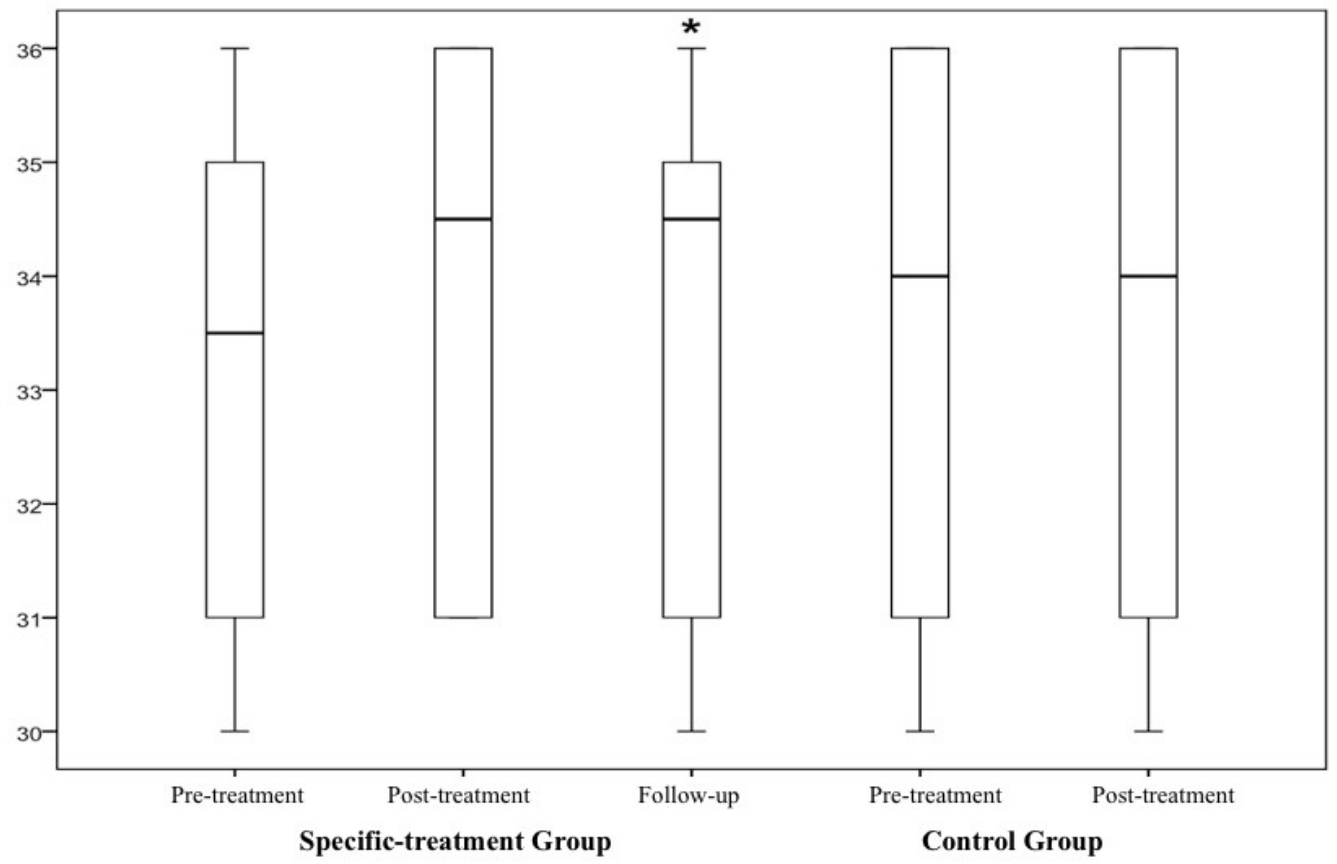

Figure 1. Postural Stroke Scale for post-stroke patients scores for groups. ${ }^{*} p=0.042$ for repeated measurements. 
Table 3 - Evolution of measurement instrument scores for both groups

\begin{tabular}{|c|c|c|c|c|c|c|c|}
\hline \multirow{2}{*}{ Variables } & \multicolumn{3}{|c|}{ Treatment group $(n=7)$} & \multicolumn{4}{|c|}{ Control group $(n=6)$} \\
\hline & Median & 10 quartile & 30 quartile & Median & 10 quartile & 3ㅇ quartile & p-value \\
\hline Pre-treatment gait time & 13 & 9 & 20 & 13 & 9.8 & 18 & 0.731 \\
\hline Post-treatment gait time & 12 & 6 & 15 & 12.3 & 7.5 & 20 & 0.945 \\
\hline Follow-up gait time & 9 & 9 & $13^{*}$ & --- & --- & --- & --- \\
\hline No. of steps - pre-treatment & 24 & 16 & 29 & 16.7 & 12 & 19.8 & 0.101 \\
\hline No. of steps - post-treatment & 20 & 14 & 27 & 15.8 & 15 & 17.3 & 0.234 \\
\hline No. of steps - follow-up & 17 & 15 & 28 & --- & --- & --- & --- \\
\hline$A B C$ Scale - pre-treatment & 119 & 66 & 134 & 69 & 55.3 & 90 & 0.138 \\
\hline ABC Scale - post-treatment & 121 & 86 & 145 & 63.2 & 51.5 & 72 & 0.05 \\
\hline ABC Scale - follow-up & 126 & 98 & $145^{*}$ & --- & --- & --- & --- \\
\hline PSS - pre-treatment & 33 & 31 & 35 & 33.5 & 30.8 & 36 & 0.731 \\
\hline PSS - post-treatment & 34 & 31 & 36 & 33.5 & 30.8 & 36 & 1 \\
\hline PSS - follow-up & 34 & 31 & $35 *$ & --- & --- & --- & --- \\
\hline FMA - pre-treatment & 23 & 14 & 26 & 24.8 & 18.8 & 31 & 0.295 \\
\hline FMA - post-treatment & 25 & 18 & 28 & 27.3 & 22.5 & 33.3 & $0.445 *$ \\
\hline FMA - follow-up & 27 & 19 & $29 *$ & --- & --- & --- & --- \\
\hline
\end{tabular}

Note: $A B C=$ Activities-specific Balance Confidence ; PSS= Postural Stroke Scale; FMA= Fugl-Meyer Assessment of Physical Performance; No.= Number; ${ }^{*}$-value $<0.05$ between repeated measures.

treadmill training in subjects with chronic CVA to improve the abnormal gait and balance pattern. Our results showed that the experimental group presented a significant improvement in walking speed, especially in the follow-up period, while the control group practically maintained the same median time. Supporting with the result obtained by Yen et al. ${ }^{(20)}$ that the treadmill training in fact promotes improvement in the gait of the subject with CVA.

Westlake and Patten ${ }^{(21)}$ conducted a double-blind randomized clinical trial with 16 patients with chronic CVA and were divided into two groups, one receiving robotic assistance through exoskeleton $(n=8)$ and the other performing treadmill walking training with partial weight support $(n=8)$. The groups received 12 sessions 3 times a week for 4 weeks, divided into slow training $(<2.5 \mathrm{~km} / \mathrm{h})$ and fast training $(>3 \mathrm{Km} / \mathrm{h})$. They used FMA, a short physical performance battery (SPPB), the balance scale of Berg (BSB) and the $6 \mathrm{~m}$ walk test. The final finding revealed significant gains for both groups, however, there was a significant difference in the pre and post-test for the walking speed on the ground, gait symmetry, in the FMA, SPPB and BSB scores in the group that made use of the exoskeleton while the group that carried out treadmill training presented improvement only in the BSB scores. In the present study there was an improvement in the motor performance evaluated through the FMA and improvement in gait performance portrayed by the smaller number of steps required to perform the TUG course and greater gait speed from the experimental group to the follow-up phase, however there was no significant difference between the groups.

Middleton, et $\mathrm{al}^{(22)}$ in their simple and randomized control study with 50 patients with chronic CVA divided into a control group $(n=23)$ and experimental group $(n=27)$ that received 3 hour of intervention daily for 10 days, were preformed balance, strength and movement amplitude exercises for both groups, but for the control group was added gait training and for the experimental group was added the training on the treadmill. They used the 3-meter walk test, $6 \mathrm{~m}$ test, BSB, Activities-specific Balance Confidende (ABC), TUG, FMA and the dynamic gait index. As a result, both groups showed improvement in gait, balance and mobility and there was no significant difference between them, demonstrating that gait training is as efficient as treadmill training. Franceschini et al. ${ }^{(23)}$ in their randomized, blinded trial, the experimental group $(n=52)$ underwent gait training on the treadmill and the control group ( $n=45)$ performed the conventional gait training, with sessions of 1 hour, 5 times a week during 4 weeks and a 6 months follow-up; used the Barthel Index, Functional Ambulatory Categories and 10- and 6-minute Walk Tests. The result corroborates with the finding of Middleton, et al. ${ }^{(22)}$, because both groups showed improvement in all measures performed at the end of therapy and in the follow-up period, i.e. the treadmill training is as effective as conventional walking training.

In our study for the experimental group, which used additional load on the non-affected limb, there was an 
improvement in the $A B C$, TUG and $10 \mathrm{~m}$ walk test indices, represented by the improvement in walking speed and in balance. The literature reports the benefits of restricting compensatory movements of the trunk and the healthy upper limb of hemiparetics. On the other hand, similar changes or changes in lower limb movement are poorly described ${ }^{(24)}$. Regnaux et al. ${ }^{(25)}$ reported the use of load on a non-affected lower limb and gait training on the treadmill by ten hemiparetics capable of walking for ten meters without assistance. They walked on the treadmill at a comfortable and steady speed during a single session, with an external load of 2 or 4 kilograms fixed to the ankle of the non-affected lower limb. Such loads have been chosen because they are suitable to restrict the use of the non-paretic lower limb without abruptly modifying or discontinuing gait. Patients achieved a significant improvement in gait velocity, step length, cadence and increase in weight gain in the paretic lower limb, as well as increased range of motion of the hip and knee. The results were maintained for at least 20 minutes after the removal of the load, which suggests that there was a change in gait pattern to compensate for the imposed situation during the treatment. In the literature it is widely known that trunk control contributes to a better seated balance, allows the standing position and walking. In the randomized and controlled study of Verheyden et al. ${ }^{(26)}$, with a group of patients with CVA, conventional therapy was performed for the control group $(n=16)$ and the experimental group $(n=17)$ received, in addition to conventional therapy, 10 hours of individual trunks exercises and supervised for 30 minutes, 4 time a week for 5 weeks using the trunk performance scale (TPS). This study concluded that there was a significant improvement in the experimental group, that specific trunk exercises bring positive effects of the selective performance of trunk movements. In the present study, we used the Postural Assessment Scale (PAS), which showed significant improvement only in the follow-up period for the experimental group, while the control group remained stable, however, in a general setting, both groups presented the maintenance of posture preserved during the performance of the proposed activities.

\section{CONCLUSION}

Treadmill therapy and weight addition in the healthy limb did not alter weight loss in the uninjured lower limb, but showed improvement in its motor function, balance in standing position and walking speed in the CVA patients.

\section{AUTHORS' CONTRIBUTIONS}

WLG: contributed to the intellectual content of this work, according to ICMJE guidelines, in the part of the critical review, revising the intellectual content of the manuscript before the final presentation. LIND and RPG: contributed to the intellectual content of this work, according to the ICMJE guidelines, in data collection and treatment, literature survey and analysis/interpretation. CMS, ACNB and GRF: contributed to the intellectual content of this work, according to the ICMJE guidelines, in data collection and treatment, literature survey, analysis/interpretation and writing of the manuscript. EWAC, ROC and NMFVL: contributed to the intellectual content of this work, according to the ICMJE guidelines, in design and development, methodological design and critical review.

\section{CONFLICTS OF INTEREST}

The authors declare that there was no conflict of interests.

\section{AUTHOR DETAILS}

2. Universidade Estadual de Campinas (Unicamp), Campinas (SP) - Brazil.

3. Universidade de Sorocaba (UNISO), São Paulo (SP), Brazil;

\section{REFERENCES}

1. Roger V, Go A, Lloyd-Jones D, Adams R, Berry J, Brown T et al. Heart Disease and Stroke Statistics--2011 Update: A Report From the American Heart Association. Circulation. 2010;123(4):e18-e209.

2. Krebs H, Volpe B. Robotics: A Rehabilitation Modality. Current Physical Medicine and Rehabilitation Reports. 2015;3(4):243-247.

3. Michael K, Allen J, Macko R. Reduced Ambulatory Activity After Stroke: The Role of Balance, Gait, and Cardiovascular Fitness. Archives of Physical Medicine and Rehabilitation. 2005;86(8):1552-1556.

4. Ivey F. Task-oriented treadmill exercise training in chronic hemiparetic stroke. The Journal of Rehabilitation Research and Development. 2008;45(2):249-260.

5. Balasubramanian C, Neptune R, Kautz S. Variability in spatiotemporal step characteristics and its relationship to walking performance poststroke. Gait \& Posture. 2009;29(3):408-414.

6. Fulk G, Reynolds C, Mondal S, Deutsch J. Predicting Home and Community Walking Activity in People With Stroke. Archives of Physical Medicine and Rehabilitation. 2010;91(10):1582-1586.

7. Harvey R. Improving poststroke recovery: Neuroplasticity and taskoriented training. Current Treatment Options in Cardiovascular Medicine. 2009;11(3):251-259.

8. McCain K, Pollo F, Baum B, Coleman S, Baker S, Smith P. Locomotor Treadmill Training With Partial Body-Weight Support Before Overground Gait in Adults With Acute Stroke: A Pilot Study. Archives of Physical Medicine and Rehabilitation. 2008;89(4):684-691.

9. Boake C, Noser E, Ro T, Baraniuk S, Gaber M, Johnson R et al. ConstraintInduced Movement Therapy During Early Stroke Rehabilitation. Neurorehabilitation and Neural Repair. 2007;21(1):14-24.

10. Ivar Gjellesvik T, Brurok B, Hoff J, Tørhaug T, Helgerud J. Effect of High Aerobic Intensity Interval Treadmill Walking in People With Chronic Stroke: A Pilot Study With One Year Follow-Up. 2017.

11. Lam J, Globas C, Cerny J, Hertler B, Uludag K, Forrester L et al. Predictors of Response to Treadmill Exercise in Stroke Survivors. Neurorehabilitation and Neural Repair. 2010;24(6):567-574.

12. Lam J, Globas C, Cerny J, Hertler B, Uludag K, Forrester L et al. Predictors of Response to Treadmill Exercise in Stroke Survivors. Neurorehabilitation and Neural Repair. 2010;24(6):567-574.

13. Haas B, Bergström E, Jamous A, Bennie A. The inter rater reliability of the original and of the modified Ashworth scale for the assessment of spasticity in patients with spinal cord injury. Spinal Cord. 1996;34(9):560564.

14. Maki T, Quagliato E, Cacho E, Paz L, Nascimento N, Inoue M et al. Estudo de confiabilidade da aplicação da escala de Fugl-Meyer no Brasil. Revista Brasileira de Fisioterapia. 2006;10(2):177-183.

15. Ng S, Hui-Chan C. The Timed Up \& Go Test: Its Reliability and Association With Lower-Limb Impairments and Locomotor Capacities in People With Chronic Stroke. Archives of Physical Medicine and Rehabilitation. 2005;86(8):1641-1647.

16. Yoneyama, SM; Roiz RM; Oliveira, MT; Oberg DT; Lima; NMVF. Validação da versão brasileira da escala de avaliação postural para pacientes após acidente vascular encefálico." Acta fisiátrica 15.2 (2016): 96-100. 
17. Collen F, Wade D, Bradshaw C. Mobility after stroke: Reliability of measures of impairment and disability. International Disability Studies. 1990;12(1):6-9.

18. Mahoney, F. I., \& Barthel, D. W. Functional evaluation: The Barthel Index: A simple index of independence useful in scoring improvement in the rehabilitation of the chronically ill. Maryland State Medical Journal, 14, (1965) 61-65.

19. Branco, PS. Validação da Versão Portuguesa da Activities-specific Balance Confidence Scale. Revista da Sociedade Portuguesa de Medicina Física e de Reabilitação 19.2 (2010): 20-25.

20. Yen C, Wang R, Liao K, Huang C, Yang Y. Gait Training-Induced Change in Corticomotor Excitability in Patients With Chronic Stroke. Neurorehabilitation and Neural Repair. 2007;22(1):22-30.

21. Westlake K, Patten C. Pilot study of Lokomat versus manual-assisted treadmill training for locomotor recovery post-stroke. Journal of NeuroEngineering and Rehabilitation. 2009;6(1):18.

22. Middleton A, Merlo-Rains A, Peters D, Greene J, Blanck E, Moran $R$ et al. Body Weight-Supported Treadmill Training Is No Better Than
Overground Training for Individuals with Chronic Stroke: A Randomized Controlled Trial. Topics in Stroke Rehabilitation. 2014;21(6):462-476.

23. Franceschini M, Carda S, Agosti M, Antenucci R, Malgrati D, Cisari C. Walking After Stroke: What Does Treadmill Training With Body Weight Support Add to Overground Gait Training in Patients Early After Stroke?: A Single-Blind, Randomized, Controlled Trial. Stroke. 2009;40(9):30793085.

24. Balasubramanian C, Bowden M, Neptune R, Kautz S. Relationship Between Step Length Asymmetry and Walking Performance in Subjects With Chronic Hemiparesis. Archives of Physical Medicine and Rehabilitation. 2007;88(1):43-49.

25. Regnaux J, Pradon D, Roche N, Robertson J, Bussel B, Dobkin B. Effects of loading the unaffected limb for one session of locomotor training on laboratory measures of gait in stroke. Clinical Biomechanics. 2008;23(6):762-768

26. Verheyden G, Vereeck L, Truijen S, Troch M, LaFosse C, Saeys W et al. Additional Exercises Improve Trunk Performance After Stroke: A Pilot Randomized Controlled Trial. Neurorehabilitation and Neural Repair. 2008;23(3):281-286 